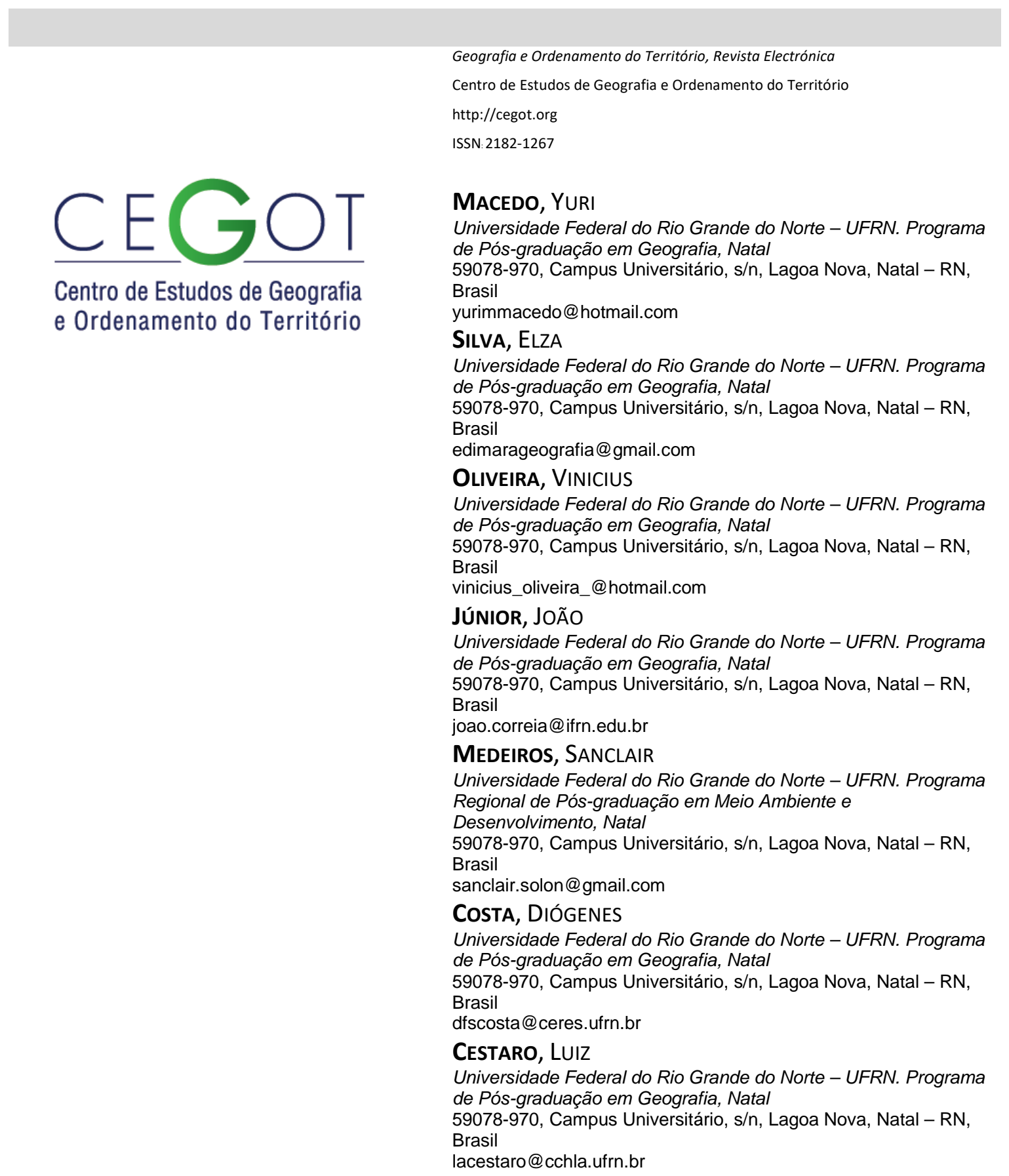

\title{
Serviços ambientais das unidades geoambientais no município de São Miguel do Gostoso/RN, Brasil
}

Environmental services of geoenvironmental units in the municipality of São Miguel do Gostoso / RN, Brasil

Referência: Macedo, Yuri et. al (2017). Serviços ambientais das unidades geoambientais no município de São Miguel do Gostoso/RN, Brasil. Revista de Geografia e Ordenamento do Território (GOT), n.o 12 (dezembro). Centro de Estudos de Geografia e Ordenamento do Território, p. 205-229, dx.doi.org/10.17127/got/2017.12.009 


\section{RESUMO}

A exploração dos recursos naturais é realizada de acordo com as necessidades da sociedade e condições ambientais dos lugares. Nesse sentido, os benefícios proporcionados pela natureza podem ser denominados serviços ambientais. No entanto, mesmo que a sociedade não explore diretamente, mas seja beneficiada por alguma interação, o serviço também é prestado. Assim, o objetivo deste trabalho é identificar os serviços ecossistêmicos e geossistêmicos encontrados nas unidades geoambientais de São Miguel do Gostoso, município costeiro do Rio Grande do Norte. A metodologia perpassa uma revisão da literatura, trabalho de campo e elaboração de mapas. Os resultados apontam que nas unidades geoambientais de São Miguel do Gostoso existem serviços semelhantes desempenhados pela vegetação e solo e serviços particulares de influência locacional.

Palavras-chave: Serviços ecossistêmicos; Serviços geossistêmicos; São Miguel do Gostoso/RN.

\section{ABSTRACT}

The exploitation of natural resources is carried out according to the society's needs and the environmental conditions of the places. In this sense, the benefits provided by nature can be termed environmental services. However, even if society does not directly explore, but is benefited by some interaction, the service is also provided. Thus, the objective of this work is to identify the ecosystem and geosystemic services found in the geoenvironmental units of São Miguel do Gostoso, coastal municipality of Rio Grande do Norte. The methodology covers a literature review, field work and mapping. The results indicate that in the geoenvironmental units of São Miguel do Gostoso there are similar services performed by vegetation and soil and private services of local influence. The results indicate that in the geoenvironmental units of São Miguel do Gostoso there are similar services performed by vegetation and soil and private services of local influence.

Keywords: Ecosystem services; Geosystems services; São Miguel do Gostoso / RN.

\section{Introdução}

O bem-estar social pode ser relacionado com diversas variáveis, a exemplo da saúde, emprego, moradia, qualidade de vida e salário. Para o Millennium Ecosystem Assessment (MEA, 2005), este bem-estar se encontra intimamente ligado à disponibilidade, quantidade e qualidade dos serviços ambientais, os quais estão sendo significativamente degradados, a nível mundial. Dessa forma, o estudo e mapeamento dos serviços ambientais tem se tornado uma importante ferramenta no que diz respeito às questões ambientais em diversas abordagens. 
A tentativa de atribuir valor aos serviços prestados pelos ecossistemas e identificar as relações entre variáveis econômicas e o ecossistema, tem seu início na década de 60 . A partir de então, diversos autores propõem padronizações e métodos de análise, a exemplo de Costanza (1989), Arrow et al. (1995), Costanza et al. (1997a), Costanza et al. (1997b), De Groot; Wilson; Boumans (2002), Millennium Ecosystem Assestment (2005), Daly; Farley (2010), Maes, et al. (2012), Haines-Young e Potschin (2012), Costanza et al. (2014).

As interações existentes entre elementos estruturais do ecossistema podem ser entendidas como funções ecossistêmicas, segundo Daly e Farley (2010). A partir destas interações e seus métodos de identificação, De Groot, Wilson e Boumans (2002) desenvolveram um sistema de categorização dos serviços prestados pelo ecossistema baseado em suas funções principais.

Tais funções foram divididas em quatro grandes categorias, sendo estas: funções de regulação a exemplo do clima, ciclo hidrológico e gases; de habitat, que versam sobre o fornecimento de habitat para fauna e flora; de produção, com foco no fornecimento de alimentos e de informação que abrigam descritores culturais, de recreação, histórias, lendas e vertentes espirituais ligadas ao ambiente (De Groot; Wilson; Boumans, 2002).

A Avaliação dos Ecossistemas do Milênio (MEA) representou outra mudança importante para os esforços para ver o meio ambiente em uma escala global e internalizá-lo no pensamento político e econômico. O seu conceito central de serviços ambientais, por exemplo, ao mesmo tempo em que enfatiza uma abordagem antropocêntrica e utilitária, propõe um quadro centrado na dependência humana, não apenas nos recursos, mas no próprio funcionamento do ecossistema, contribuindo para tornar visível uma ampla gama de funções ecológicas e biofísicas tomadas para como concedidas a sociedade. O MEA contribuiu para uma compreensão mais ampla da grande escala de impactos humanos, suas pegadas e suas consequências econômicas e sociais atuais e futuras. (Brondízio et al., 2010).

Por outro lado, a Common International Classification of Ecosystem Services (CICES), elaborada por Haines-Young e Potschin (2013), propôs uma classificação internacional para os serviços ecossistêmicos, com o objetivo de atender as diferentes perspectivas que evoluíram em torno deste conceito, e vem sendo amplamente aceita e aplicada em diversos estudos. A mesma se estrutura nas seções de Serviços de Provisão, Serviços de Regulação e 
Manutenção e Serviços Culturais. Por sua vez, as seções se fragmentam em divisões, e estas se dividem em grupos.

Como apresentando anteriormente, muitas das pesquisas têm seu foco na valoração dos Serviços Ambientais (SE), mas nem todos os SE podem ser descritos em termos econômicos ou monetários, de acordo com Chan, Satterfield e Goldstein (2012), especialmente os valores associados aos serviços ambientais culturais e espirituais (Maes; Crossman; Burkhard, 2016).

As definições da maioria das categorias de serviços culturais são vagas e, para muitos deles, é difícil estabelecer relações significativas entre as estruturas e funções do ecossistema e a satisfação das necessidades e desejos humanos (Daniel et al., 2012).

Com isto, esta pesquisa objetiva realizar por meio de revisões bibliográficas, atividades de campo e elaboração do mapeamento de serviços ambientais, a identificação dos principais S.E do município de São Miguel do Gostoso no Estado do Rio Grande do Norte, de acordo com suas unidades geoambientais identificadas, a partir da aplicação da Common International Classification of Ecosystem Services (CICES), elaborado por Haines-Young e Potschin (2013).

\section{2. Área de Estudo}

O município, objeto de estudo, tem como limites ao Norte o Oceano Atlântico; sua porção Sul tem fronteiras com o município de Touros; a Leste o Oceano Atlântico e Touros e a Oeste (Fig. 01) estão localizados os municípios de Pedra Grande e Parazinho. O mesmo se encontra localizado na Microrregião do IBGE denominada de Litoral Nordeste e na Zona Homogênea do Planejamento intitulada de Litoral Norte (IDEMA, 2008). 


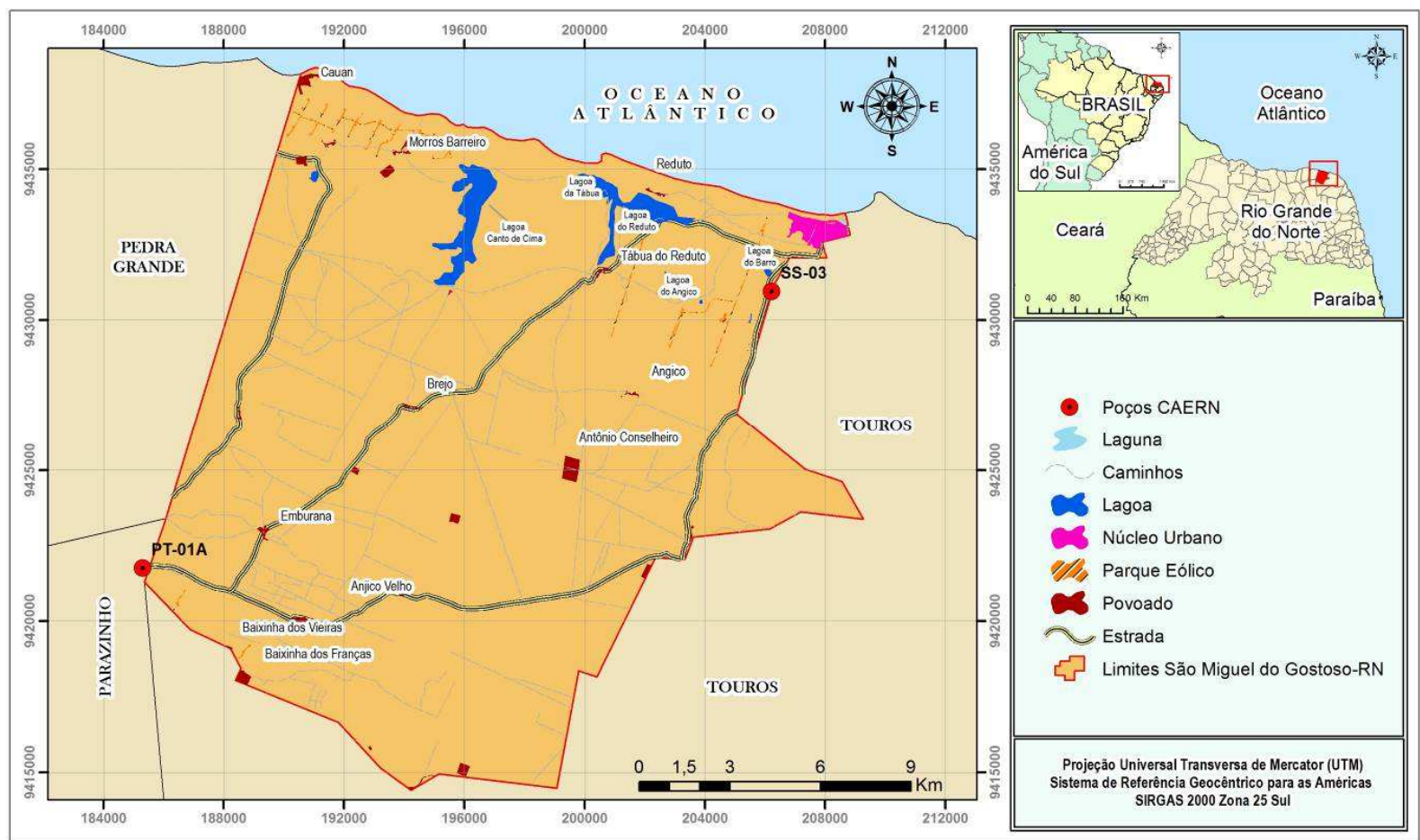

Figura 01: Mapa de Localização do Município de São Miguel do Gostoso-RN. Fonte: Os autores (2017), baseado em CPRM (2010); IDEMA (2007).

Com uma área de $342,45 \mathrm{~km}^{2}$, equivalente a 0,65\% da superfície estadual, o município tem coordenadas geográficas: Latitude: 5 $07^{\prime}$ '29" Sul e Longitude: 35을 $38^{\prime}$ 21" Oeste e se encontra a uma distância de aproximadamente $102 \mathrm{~km}$ da capital do Estado, Natal (IDEMA, 2008). O acesso é feito pela BR- 101 no sentido Natal-Touros e RN-221 que possibilita o acesso de Touros a São Miguel do Gostoso.

\section{Metodologia}

\subsection{Confecção dos quadros referentes aos serviços ambientais}

Todos os quadros referentes aos serviços ambientais do município de São Miguel do Gostoso foram preenchidos a partir da aplicação da Common International Classification of Ecosystem Services (CICES) elaborado por Haines-Young e Potschin (2013), de acordo com as suas diversas classificações de Serviços de Provisão, Serviços de Regulação e Manutenção e Serviços Culturais. 


\subsection{Confecção dos mapas}

A elaboração do acervo cartográfico deste trabalho obedeceu três fases principais: cartografia preliminar; trabalho de campo; e cartografia final. Vale ressaltar que a primeira e a última fase citadas foram realizadas através do sistema de informação geográfica (SIG), com auxílio do Software ArcGis 10.3. Na confecção cartográfica preliminar, as unidades geoambientais e as diversas classes de cobertura da terra foram previamente identificadas, através da utilização de um banco de dados georreferenciados, dos tipos vetoriais e raster, disponibilizado de forma gratuita por diversos órgãos públicos e empresa privada, como o Instituto de Desenvolvimento Sustentável e Meio Ambiente do Rio Grande do Norte (IDEMA), a Companhia de Pesquisa de Recursos Minerais (CPRM), o Instituto Brasileiro de Geografia e Estatística (IBGE), o Instituto Nacional de Pesquisas Espaciais (INPE) (projeto TOPODATA, imagem SRTM, resolução espacial de 30m) e o Google Earth (Satélite Geoeye, data da imagem 04/2014 e resolução espacial de $3 \mathrm{~m}$ ). Nesta fase, foi elaborada uma base cartográfica preliminar, com a identificação de unidades geoambientais e classes de cobertura da terra, a serem validadas no trabalho de campo.

Posteriormente, o trabalho empírico permitiu o reconhecimento de campo, com a utilização de pontos de descrição georreferenciados, ao longo de estradas internas municipais, rendendo perfis de descrição, seguindo a metodologia de transectos (Apud Cavalcanti, 2014). O mapeamento deu-se, portanto, com base na forma da paisagem, geomorfologia e descrições de campo, através do preenchimento de uma ficha/questionário táctil-visual, adaptada de Souza (2005). Após as informações obtidas durante o trabalho de campo, a cartografia preliminar foi atualizada e finalizada, gerando cinco mapas descritos a seguir, com escala de mapeamento de 1:25.000 e escala de apresentação cartográfica de 1:100.000, em folha de formato A3.

O mapa de delimitação das Unidades Geoambientais subdividiu o município de São Miguel do Gostoso em quatro grandes classes, tais como: Baixo Platô Interiorano, Tabuleiro Costeiro, Planície Costeira e Planície Fluvial-Lacustre/Lagunar. Ambas as unidades foram definidas principalmente por meio da análise da variação topográfica da área e as especificidades das suas características geológicas, geomorfológicas e, pedológicas. 
Dessa forma, o Baixo Platô Interiorano, corresponde à cota que varia entre $50 \mathrm{~m}$ e $120 \mathrm{~m}$, sendo predominantemente localizada sobre a Formação Jandaíra. Por outro lado, o Tabuleiro Costeiro corresponde à área com cota que varia entre $10 \mathrm{~m}$ e $50 \mathrm{~m}$, sendo predominantemente localizada sobre a Formação Barreiras. Já a Planície Costeira foi delimitada a partir de cotas inferiores a 10 metros, situada sobre a Formação de Praias e Dunas e presença de neossolos quartzarênicos. Por fim, a Planície Fluvio-Lacustre/Lagunar se localiza em áreas com topografia plana e cotas altimétricas inferiores às das unidades vizinhas, já descritas anteriormente, onde é possível o transporte e o acúmulo de material conforme os seus diversos componentes: rios, lagoas e lagunas.

Com relação ao mapa de cobertura da terra, após o reconhecimento empírico da área, através do trabalho de campo, o mesmo foi composto por 15 classes principais, obtidas através de três procedimentos: vetorização através do software Google Earth (Satélite Geoeye, data da imagem 04/2014 e resolução espacial de 3m); classificação supervisionada por máxima verossimilhança (MAXVER) e; arquivo vetorial do tipo shape file (Quadro 01).

\begin{tabular}{|c|c|}
\hline Classes de Cobertura da Terra & Fonte de dados \\
\hline Faixa de praia & Vetorização \\
\hline Falésia & Vetorização \\
\hline Duna com vegetação herbácea e arbustiva & Classificação supervisionada \\
\hline Duna com vegetação herbácea & Classificação supervisionada \\
\hline Duna com ausência de vegetação & Classificação supervisionada \\
\hline Caatinga hipoxerófila primária & Classificação supervisionada \\
\hline Caatinga hipoxerófila secundária & Classificação supervisionada \\
\hline Mata ciliar de carnaúba & Vetorização \\
\hline Campo de várzea & Vetorização \\
\hline Lagoa & Shape file IDEMA e Vetorização \\
\hline Laguna & Vetorização \\
\hline Agricultura & Vetorizizicação supervisionada \\
\hline Povoano urbano & Vetorizão \\
\hline Puão
\end{tabular}

Quadro 01: Classes e fonte de dados do mapa de cobertura da terra. Fonte: Os autores, 2017. 
Os mapas referentes aos serviços ambientais de provisão, e regulação e manutenção, foram construídos a partir do relacionamento dos dados das suas respectivas tabelas de serviços ambientais, já citadas, com o arquivo vetorial das unidades geoambientais do município. Para tanto, foi adicionada uma coluna na tabela de atributos deste arquivo vetorial do tipo Shape File, e inserida a quantidade de serviços ambientais prestados por cada unidade (linhas), permitindo que fosse gerado um mapa cloroplético. Por outro lado, devido à dificuldade em espacializar os dados culturais do município, o mapa de serviços ambientais culturais foi elaborado a partir de registros fotográficos, georreferenciados, e disponíveis no Software Google Earth. Realizou-se um levantamento quantitativo dos registros, levando em consideração o local destes, relacionando-o com as unidades geoambientais previamente delimitadas no estudo. A partir desta informação foi possível elaborar um arquivo vetorial de pontos, onde cada um deste representa um serviço ambiental cultural expresso por uma fotografia.

\section{Apresentação dos resultados}

\subsection{Unidades geoambientais e cobertura da terra do município de São Miguel do Gostoso}

Em relação às unidades geoambientais classificadas para o município de São Miguel do Gostoso, foram definidas 4 (quatro) grandes unidades, de nível 1 nesta classificação. São elas, do litoral para o continente (norte-sul): Planície Costeira; Planície Flúviolacustre/lagunar; Tabuleiro Costeiro; Baixo Platô.

Cada uma destas unidades (nível 1) foi subdividida em mais 2 níveis (níveis 2 e/ou 3). 0 quadro 02 mostra como foi feita esta subdivisão, em função de cada unidade maior de nível 1. Para cada unidade foram relacionados elementos ambientais característicos de cada uma, sendo estes: Geologia; Geomorfologia; Solos; Hidrografia; e Vegetação. Essa correlação é um fundamento da análise geoambiental, para entender a configuração e funcionalidade ambiental em todos seus componentes, por unidade geoambiental. 


\begin{tabular}{|c|c|c|c|c|c|c|c|}
\hline \multicolumn{2}{|c|}{ UNIDADES GEOAMBIENTAIS } & \multicolumn{6}{|c|}{ CARACTERÍSTICAS AMBIENTAIS DOMINANTES } \\
\hline NÍVEL 1 & NÍVEL 2 & GEOLOGIA & GEOMORFOLOGIA & SOLO & HIDROGRAFIA & VEGETAÇÃO & COBERTURA/USO \\
\hline \multirow{3}{*}{$\begin{array}{l}\text { PLANÍCIE } \\
\text { COSTEIRA }\end{array}$} & Praia & $\begin{array}{l}\text { Depósitos } \\
\text { litorâneos, } \\
\text { Formação } \\
\text { Barreiras, } \\
\text { Depósitos eólicos } \\
\text { carbonatados. }\end{array}$ & $\begin{array}{l}\text { Sistema Praial, Falésia, } \\
\text { Planície de Deflação }\end{array}$ & \multirow{3}{*}{$\begin{array}{l}\text { Neossolo } \\
\text { quartzarênico }\end{array}$} & \multirow{3}{*}{$\begin{array}{l}\text { Bacia da Faixa Norte de } \\
\text { Escoamento Difuso. } \\
\text { Vários pontos de } \\
\text { convergência de fluxos }\end{array}$} & \multirow{3}{*}{$\begin{array}{l}\text { Vegetação psamófila (Ipomea } \\
\text { Littoralis. Ipomoea pes-caprae) } \\
\text { salsa da praia, cipó da praia. }\end{array}$} & $\begin{array}{l}\text { Falésia, antepraia; estirâncio; } \\
\text { núcleo urbano; povoados e; } \\
\text { parque eólico. }\end{array}$ \\
\hline & Dunas móveis & $\begin{array}{l}\text { Depósitos } \\
\text { litorâneos }\end{array}$ & Dunas & & & & Pós-praia, núcleo urbano. \\
\hline & $\begin{array}{l}\text { Dunas } \\
\text { vegetadas com } \\
\text { herbáceas e } \\
\text { arbustos }\end{array}$ & $\begin{array}{l}\text { Depósitos } \\
\text { litorâneos }\end{array}$ & Dunas & & & & $\begin{array}{l}\text { Povoados; parque eólico; e } \\
\text { núcleo urbano. }\end{array}$ \\
\hline \multirow{3}{*}{$\begin{array}{l}\text { PLANÍCIE } \\
\text { FLUVIO- } \\
\text { LACUSTRE/LAG } \\
\text { UNAR }\end{array}$} & Planície fluvial & \multirow{2}{*}{$\begin{array}{l}\text { Formação } \\
\text { Barreiras; Jandaíra. } \\
\text { Depósitos Aluviais } \\
\text { recentes }\end{array}$} & \multirow{3}{*}{$\begin{array}{l}\text { Vale fluviais e planícies } \\
\text { de inundações fluviais, } \\
\text { lacustre e lagunares. }\end{array}$} & \multirow{3}{*}{$\begin{array}{l}\text { Neossolos } \\
\text { quartzarênicos } \\
\text { Flúvicos } \\
\text { Gleissolos } \\
\text { hidromórficos }\end{array}$} & \multirow{3}{*}{$\begin{array}{l}\text { Faixa Norte de } \\
\text { Escoamento Difuso; } \\
\text { Aquíferos Jandaíra e } \\
\text { Barreiras; Rios } \\
\text { intermitentes/ efêmeros; } \\
\text { lagoas temporárias; } \\
\text { lagunas perenes. }\end{array}$} & \multirow{3}{*}{$\begin{array}{c}\text { Carnaúba; gramíneas } \\
\text { herbáceas halófitas e caatinga } \\
\text { hipoxerófila }\end{array}$} & $\begin{array}{l}\text { Planície de inundação fluvial; } \\
\text { Área de várzea; Mata ciliar } \\
\text { com carnaúba. }\end{array}$ \\
\hline & $\begin{array}{l}\text { Planície } \\
\text { Lacustre }\end{array}$ & & & & & & $\begin{array}{l}\text { Área de várzea; Mata ciliar } \\
\text { com carnaúba. }\end{array}$ \\
\hline & Planície Lagunar & $\begin{array}{l}\text { Depósitos } \\
\text { litorâneos }\end{array}$ & & & & & Área de várzea \\
\hline $\begin{array}{l}\text { TABULEIRO } \\
\text { COSTEIRO }\end{array}$ & $\begin{array}{l}\text { TABULEIRO } \\
\text { COSTEIRO }\end{array}$ & Formação Barreiras & $\begin{array}{l}\text { Relevo tabular, plano a } \\
\text { pouco ondulado. }\end{array}$ & $\begin{array}{l}\text { Latossolo } \\
\text { Vermelho- } \\
\text { amarelo }\end{array}$ & $\begin{array}{l}\text { Faixa Norte de } \\
\text { Escoamento Difuso. } \\
\begin{array}{l}\text { Mediana densidade de } \\
\text { drenagem. } \\
\text { efêmeros }\end{array} \\
\end{array}$ & Caatinga hipoxerófila & $\begin{array}{l}\text { Núcleo Urbano; Povoados; e } \\
\text { Parque eólico. }\end{array}$ \\
\hline BAIXO PLATÔ & BAIXO PLATÔ & Formação Jandaíra & $\begin{array}{l}\text { Relevo tabular, plano a } \\
\text { pouco ondulado. }\end{array}$ & Luvissolo & $\begin{array}{lr}\text { Faixa Norte de } & \text { de } \\
\text { Escoamento Difuso. } \\
\text { Baixa densidade de } \\
\begin{array}{l}\text { drenagem. } \\
\text { efêmeros. }\end{array} \\
\end{array}$ & Caatinga hipoxerófila & $\begin{array}{l}\text { Núcleo Urbano; Povoados; e } \\
\text { Parque eólico. }\end{array}$ \\
\hline
\end{tabular}

Quadro 02 - Compartimentação das unidades geoambientais superiores e inferiores do município de São Miguel do Gostoso-RN. Fonte: Os autores, 2017. 
A Planície Flúvio-Lacustre/Lagunar é a segunda grande unidade classificada para o município. Nesta foram definidas as seguintes subunidades de nível 2: Planície fluvial; Planície Lacustre; Planície Lagunar. Todas estas subunidades foram caracterizadas com geomorfologia, solos, hidrografia e vegetação iguais. Trata-se de relevo de vale fluviais e planícies de inundações fluviais, lacustre e lagunares. Solos do tipo neossolos quartzarênicos flúvicos e gleissolos hidromórficos. E hidrografia de bacia da faixa norte de escoamento difuso, com vários pontos de convergência de fluxos. Com potencialidades aquíferas no Jandaíra e/ou Barreiras, com rios intermitentes e/ou efêmeros; lagoas temporárias e lagunas perenes. Vegetação de carnaúba, gramíneas herbáceas halófitas e caatinga hipoxerófila em alguns pontos isolados.

Neste contexto, a subunidade de Planície Fluvial (nível 2) tem como unidades elementares as seguintes: planície de inundação fluvial; área de várzea; mata ciliar com carnaúba. Suas características geológicas são inerentes às duas formações: Formação Barreiras (arenitos, siltitos e argilitos); e Formação Jandaíra (calcário). Porém, os depósitos aluviais recentes é a formação que mais se adequa especificamente a esta subunidade. A Planície Lacustre tem as mesmas características ambientais, porém com ocupações das seguintes unidades elementares: área de várzea; mata ciliar com carnaúba. Já a subunidade de Planície Lagunar apresenta apenas ocupação elementar de Área de várzea, com geologia associada aos Depósitos litorâneos (areias finas e grossas).

O Tabuleiro Costeiro é outra grande unidade geoambiental definida para o município. Nesta não há subdivisões de nível 2, apenas unidades elementares de ocupação com: núcleo urbano; povoados; e parque eólico. A geologia predominante reside nos sedimentos consolidados a pouco consolidados da Formação Barreiras (arenitos, siltitos e argilitos); comrelevo tabular, plano a pouco ondulado. Solo do tipo latossolo vermelho-amarelo. Hidrografia inerente à bacia da faixa norte de escoamento difuso; com vários pontos de convergência de fluxo, mediana densidade de drenagem e rios efêmeros. A vegetação predominante é da formação de caatinga hipoxerófila fechada (densa).

Por último, definiu-se a unidade maior do Baixo Platô. A qual, assim como a anterior, não tem subdivisões de nível 2, apenas as mesmas ocupações elementares (nível 3) do Tabuleiro Costeiro. Já a geologia predominante à formação Jandaíra (Calcário), com relevo tabular, 
plano a pouco ondulado. Solo associado ao calcário, do tipo luvissolo (antigo podzólico vermelho-amarelo) ou cambissolo. Com hidrografia inerente à Bacia da Faixa Norte de Escoamento Difuso, com baixa densidade de drenagem e rios efêmeros. A vegetação mais pronunciada é a caatinga hipoxerófila aberta (savana).

O mapeamento realizado destas unidades e suas subdivisões mapeáveis em escala 1:50.000, podem ser visualizadas na figura 02 . Em que o critério predominante foi a topografia (curvas de nível), assim como trabalho de campo e classificação supervisionada de imagens de satélite.

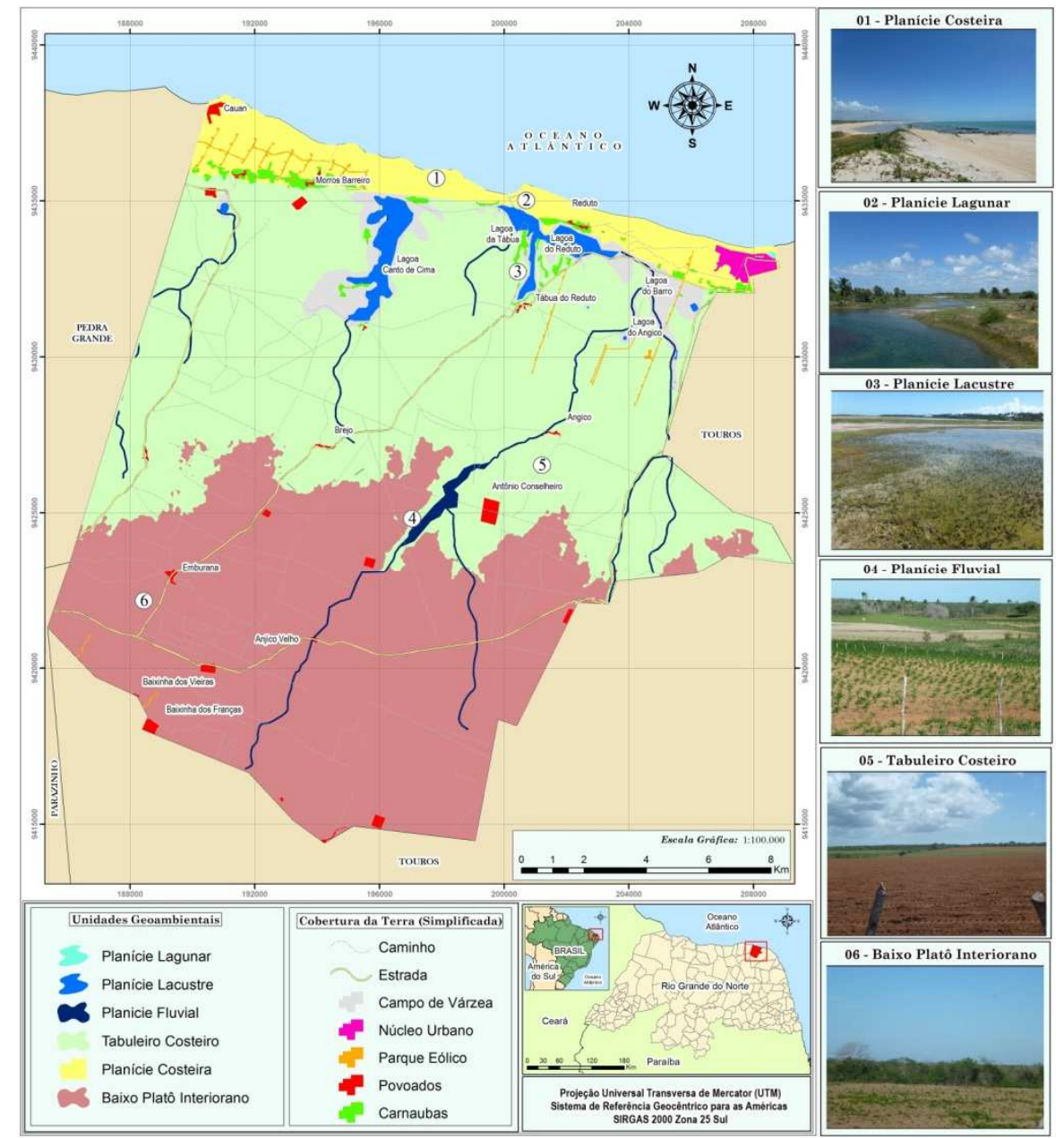

Figura 02 - Mapa de unidades geoambientais ilustrado, do município de São Miguel do Gostoso. Fonte: Curvas de nível (SRTM/TOPODATA-INPE); Trabalho de campo. Elaboração: Os autores, 2017.

Por outro lado, a cobertura da terra do município de São Miguel do Gostoso-RN também é bastante diversa, onde foram identificadas 15 classes principais. Ao analisar o Quadro 03 e Figura 03 podemos perceber que a classe de cobertura da terra que ocupa a maior área do 
município de São Miguel do Gostoso-RN é de caatinga hipoxerófila primária. Esse é um dado importante, pois, ao contrário da maioria dos demais municípios do estado do Rio Grande do Norte, São Miguel do Gostoso, ainda tem preservado em sua área territorial uma parcela significativa de vegetação nativa, tornando esta, uma área potencial para a implantação de uma unidade de conservação da caatinga hipoxerófila.

\begin{tabular}{|c|c|c|}
\hline Classes & Área (hectares) & \% de ocupação \\
\hline Povoados & 189,8537 & 0,6 \\
\hline Caatinga hipoxerófila secundária & 5950,3231 & 17,4 \\
\hline Caatinga hipoxerófila primária & 17240,7319 & 50,3 \\
\hline Agricultura & 6578,6642 & 19,2 \\
\hline Campo de várzea & 1234,2521 & 3,6 \\
\hline Carnaúbas & 255,4783 & 0,7 \\
\hline Duna com vegetação herbácea e & 754,6084 & 2,2 \\
\hline arbustiva & 284,2514 & 0,8 \\
\hline Duna com ausência de vegetação & 151,6693 & 0,4 \\
\hline Faixa de praia & 542,6106 & 1,6 \\
\hline Lagoa & 817,1049 & 2,4 \\
\hline Duna com vegetação herbácea & 128,361 & 0,4 \\
\hline Núcleo urbano & 2,8919 & 0,008 \\
\hline Falésia & 3,6696 & 0,01 \\
\hline Laguna & 110,5254 & 0,3 \\
\hline Parque eólico & $\mathbf{3 4 . 2 4 5}$ & 100 \\
\hline Total & & \\
\hline
\end{tabular}

Quadro 03 - Ocupação territorial das classes de cobertura da terra do município de São Miguel do Gostoso. Fonte: Os autores, 2017.

Entretanto, podemos perceber que a agricultura e a caatinga hipoxerófila secundária (ou seja, aquela que já foi alterada e está em processo de regeneração) juntas somam $36.6 \%$ da ocupação territorial do município. Sobre isso, podemos auferir, ao analisar a Figura 03, que a caatinga hipoxerófila secundária se localiza em torno das áreas de agricultura, indicando que esta atividade provavelmente já degradou anteriormente estes locais, onde a caatinga agora está em processo de regeneração, e migrou para as atuais áreas de agricultura. Estas informações se tornam relevantes a partir do momento em que a agricultura, apesar de ser 
importante para a economia do município e para a subsistência de boa parte do seu contingente populacional, é uma atividade que promove o desflorestamento da caatinga, assim como, dependendo da sua forma de produção, pode contaminar o solo e as planícies de inundações fluviais com produtos químicos que compõem os defensivos agrícolas.

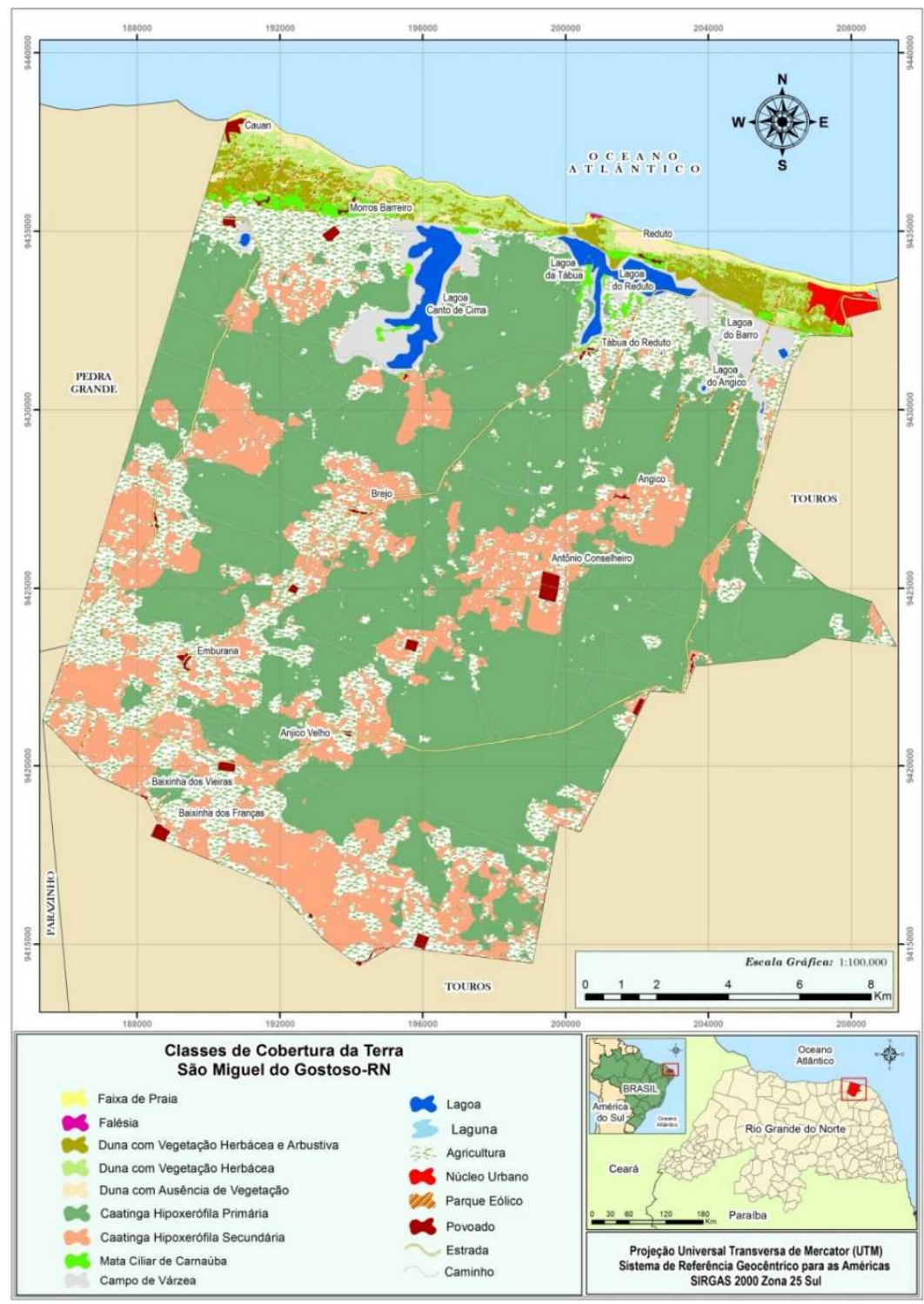

Figura 03: Mapa de cobertura da terra do município de São Miguel do Gostoso-RN. Fonte: Os autores, 2017.

\subsection{Unidades geoambientais e cobertura da terra do município de São Miguel do}

\section{Gostoso}

No município de São Miguel do Gostoso foram identificados os serviços ambientais de provisão, devidamente agrupados de acordo com a classificação CICES, e que se distribuem 
de forma variada ao longo das suas unidades geoambientais. A grande parte dos serviços ambientais de provisão se encontram, respectivamente, nas unidades geoambientais do Baixo Platô Interiorano e do Tabuleiro Costeiro. Em terceiro lugar podemos citar a Planície Fluvio-Lacustre/Lagunar e em seguida a Planície Costeira.

Conforme padronização estabelecida pela CICES, as divisões de nutrição, materiais e energia, se subdividem em grupos. A divisão de nutrição é agrupada em biomassa e água para consumo direto. A divisão de materiais é agrupada em biomassa e água para consumo indireto. Por fim, a divisão de energia é fragmentada em fontes de energia à base de biomassa e energia mecânica.

Dessa forma, na divisão de nutrição, o grupo de biomassa subdivide-se nas classes: culturas, animais criados, plantas e animais selvagens. Com relação à classe de culturas, foram identificados, através dos dados do Censo Agropecuário (BRASIL, 2007), 13 diferentes tipos de cultivos agrícolas (Quadro 04). Grande parte destas culturas localizam-se nas unidades geoambientais do Baixo Platô Interiorano e do Tabuleiro Costeiro, secundariamente na Planície Fluvio-Lacustre/Lagunar e em menor quantidade na Planície Costeira.

\begin{tabular}{|c|c|c|c|c|}
\hline Tipo da Classe & *Nome Científico & Área colhida & **Produção (t) & Tipo de Uso \\
\hline Abacaxi & Ananas comosus L. Merril & 250 & 6250 & Nutrição Humana \\
\hline Acerola & Malpighia punicifolia L. & - & - & Nutrição Humana \\
\hline Batata-doce & Ipomoea batatas & 65 & 520 & Nutrição Humana \\
\hline Feijão & Phaseolus vulgaris & 250 & 120 & Nutrição Humana \\
\hline Mandioca & Manihot esculenta Crantz & 2.650 & 31800 & Nutrição Humana \\
\hline Melão & Cucumis melo & 80 & 3200 & Nutrição Humana \\
\hline Banana & Musa spp & - & - & Nutrição Humana \\
\hline Milho & Zea mays & 600 & 330 & Nutrição Humana \\
\hline Sorgo granífero & Sorghum vulgare & 500 & 600 & Nutrição Animal \\
\hline Abacate & Persea americana & 2 & 26 & Nutrição Humana \\
\hline Coco-da-baía & Cocos nucifera & 2500 & 6250 & Nutrição Humana \\
\hline Manga & Mangifera indica L. & 58 & 696 & Nutrição Humana \\
\hline Sisal ou Agave & Aggave sisalana & 33 & Nutrição Animal \\
\hline
\end{tabular}

Quadro 04: Cultivos Agrícolas do município de São Miguel do Gostoso-RN. Fonte: *Nome científico baseado nas informações divulgadas pela EMBRAPA. **Produção (BRASIL, 2007). 
No que diz respeito aos animais de criação, foram identificados bovinos, suínos, ovinos, aves, caprinos e abelha europeia, que se distribuem principalmente nas unidades geoambientais do Baixo Platô Interiorano, Tabuleiro Costeiro e Planície Costeira. De acordo com Brasil (2007), o rebanho de bovinos, suínos, ovinos e caprinos foi de aproximadamente, 3.869, 364, 710 e 1.500 cabeças, respectivamente. Segundo a mesma fonte, no município de São Miguel do Gostoso foram produzidos 583.000 litros de leite, 20.000 dúzias de ovos de galinha e $3.480 \mathrm{Kg}$ de mel de abelha africana.

Com relação às plantas selvagens utilizadas para nutrição humana e/ou animal, foram identificadas 06 espécies principais, tais como: a Carnaúba (Copernicia prunifera), utilizada para nutrição animal e localizada principalmente na Planície Fluvio-Lacustre/Lagunar, mas também com ocorrência na Planície Costeira; o Juazeiro (Ziziphus joazeiro), utilizado tanto para a nutrição humana quanto animal, e localizado no Baixo Platô Interiorano e no Tabuleiro Costeiro; o Mandacaru ou Cardeiro (Cereus jamacaru), servido para nutrição animal, e localizado em todas as unidades geoambientais; o Caju (Anacardium occidentale), utilizado para alimentação humana, e localizado também todas as unidades geoambientais; a Mangaba (Hancornia speciosa), utilizada para nutrição humana, e localizada principalmente no Tabuleiro e Planície Costeira e; o Umbuzeiro (Spondias tuberosa), utilizada também para alimentação humana e localizado no Baixo Platô Interiorano, assim como, no Tabuleiro Costeiro.

De acordo com a divisão de nutrição e grupo de biomassa, foram identificados 11 tipos de animais selvagens utilizados para a nutrição humana, tais como: Abelha Jandaíra (Melipona subnitida), Teju (Tupinambis), Tatu-peba (Euphractus sexcinctus), Tatu-bola (Tolypeutes), Rolinha (Columbina), Juriti (Leptotila), Roedores, Répteis, Peixes e Crustáceos.

Ainda sobre a divisão nutrição, o grupo de água para consumo direto subdivide-se em água de superfície potável e água subterrânea potável. A água potável superficial é coletada, pelos moradores do município de São Miguel do Gostoso, por meio de cisternas, principalmente nos períodos de maiores precipitações pluviométricas, contribuindo para a estocagem de água que lhes servem nos períodos de estiagem. Essas cisternas podem ser encontradas em todas as unidades geoambientais. Entretanto, a água potável de origem 
subterrânea é coletada através de poços localizados principalmente no Baixo Platô Interiorano, no Tabuleiro Costeiro e na Planície Costeira.

Com relação à divisão de materiais, o grupo de biomassa subdivide-se nas classes: fibras/materiais de plantas e animais para uso direto ou transformação, materiais de plantas ou animais para uso agrícola e materiais genéticos. Relacionadas à primeira classe citada, foram identificadas 09 espécies que possuem diversas utilidades, tanto para utilização na área da construção civil, como para a fabricação de artesanato, quanto para remédios naturais e medicamentos dentre elas, citamos a Carnaúba, a Catigueira e o Mandacaru.

A Carnaúba (Copernicia prunifera), encontrada principalmente na Planície FluvioLacustre/Lagunar, é a espécie que possuí uma maior diversidade de utilização, desde a cera extraída das suas folhas, o óleo extraído do seu fruto, o tronco utilizado na construção civil, até as suas fibras para fabricação de artesanatos. Por sua vez, a Catingueira (Caesalpinia pyramidalis Tul), encontrada principalmente no Baixo Platô Interiorano, pode ser utilizada para a fabricação de estacas, moirões, varas e cabos de ferramentas, assim como, uso medicinal, onde suas folhas são utilizadas no tratamento de dores no estômago, como diarreias.

O Mandacaru (Cereus jamacaru), também conhecido como Cardeiro, pode ser encontrado principalmente no Baixo Platô Interiorano e no Tabuleiro Costeiro. Sua utilização nessa classe é medicinal, a partir do aproveitamento das suas flores e caule para o tratamento de retenção de urina. No que concerne à divisão de materiais, e grupo de biomassa, podemos destacar os materiais de plantas ou animais para uso agrícola, que são utilizados como adubos, como no caso de fezes de animais e folhagem (serra pilheira), que abastecem o solo com nutrientes. Com relação aos materiais genéticos, ressalta-se o uso de sementes.

Por fim, no que diz respeito à divisão de energia, o grupo fontes de energia à base de biomassa, refere-se a recursos à base de plantas, como por exemplo, a vegetação lenhosa utilizada como matriz energética em casas de farinha, padarias e cerâmicas. A produção de lenha para esta atividade, segundo Brasil (2007), totalizou $3.950 \mathrm{~m}^{3}$, e de carvão vegetal, cerca de 5 toneladas. O grupo fontes de energia mecânica se resume a energia à base de animais, como a utilização de equinos, muares e asininos, utilizados como meio de 
transporte ou de movimentação de máquinas, tal como em alguns casos na moagem de mandioca para fabricação de farinha.

\subsection{Serviços de regulação e manutenção}

Os serviços de regulação e manutenção são encontrados em São Miguel do Gostoso. De ordem ecossistêmica ou geossistêmica, tais serviços são percebidos nas unidades geoambientais (planície costeira, fluvio lacustre, Tabuleiros Costeiros e Baixos Platôs).

Alguns elementos paisagísticos são comuns a todas as unidades como Cobertura vegetal, Estrutura geológica e Formas de relevo. Assim, os serviços disponibilizados se apresentam com maior ou menos intensidade de acordo com a unidade de paisagem. Foram identificados no total 67 serviços assim distribuídos: 14 na planície costeira, 18 na planície fluviolacustre lagunar, 18 no tabuleiro costeiro e 17 no Baixo Platô.

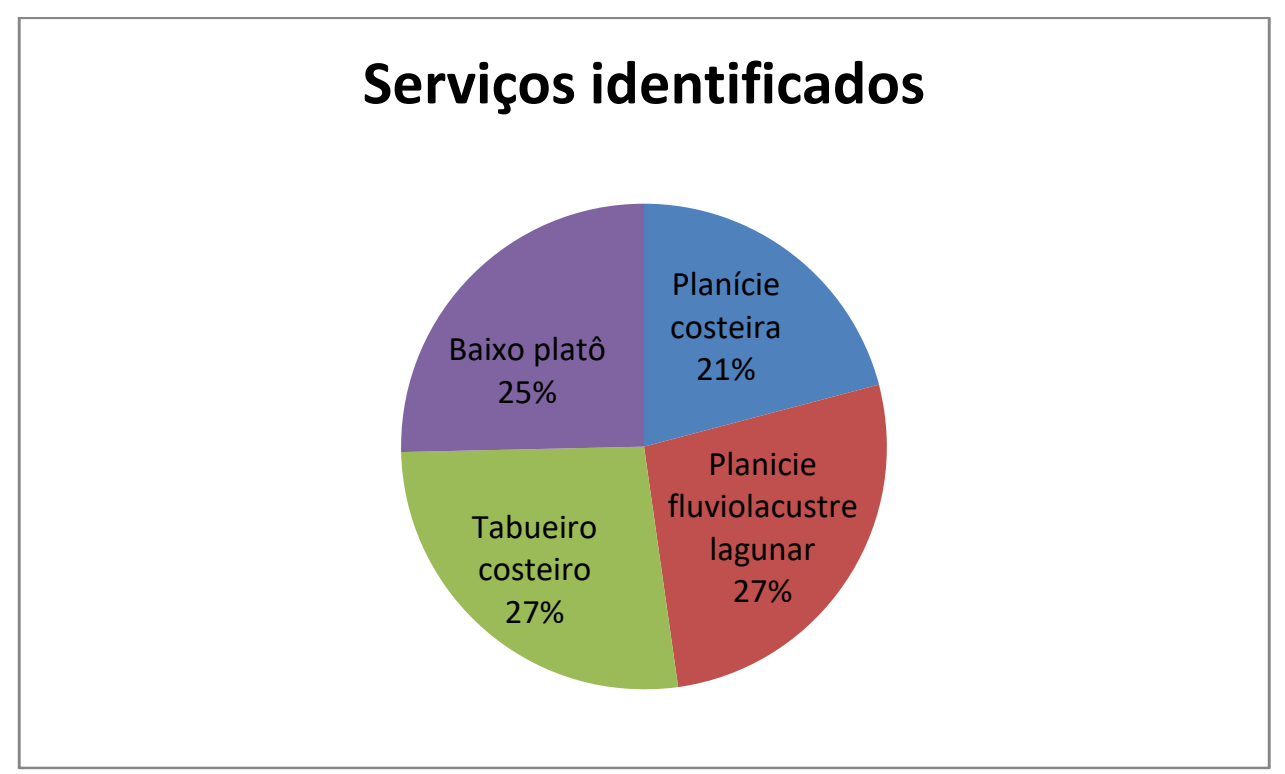

Gráfico 01: Distribuição percentual dos serviços por unidade geoambiental em São Miguel. Fonte: Os autores, 2017.

Serviços como sequestro de carbono pelos ecossistemas, influência da vegetação na circulação do ar e amenização da temperatura são encontrados em todas as unidades geoambientais. No entanto, serviços influenciados pela condição espacial são percebidos em cada unidade. 
Na planície costeira, a vegetação psamófila exerce função de estabilização dos sedimentos arenosos litorâneos que sustentam as dunas frontais móveis, dunas fixas herbáceas, dunas fixas vegetadas por arbustos e planície de deflação. Ainda é possível perceber tal função protetora na falésia de Tourinhos. Nos trechos vegetados a remobilização de sedimentos é atenuada. No entanto, nas superfícies expostas à ação mecânica pluvial e eólica, a erosão é bastante evidente.

O papel de estabilização desempenhado pela cobertura vegetal é fundamental na contenção de sedimentos em relação à construção civil. Tanto na sede do município quanto na comunidade do Reduto e algumas vias de acesso na porção NW, muitas casas e estradas foram construídas na superfície de transferência de sedimentos arenosos. Se não fosse pela cobertura vegetal, areias de diversas granulometrias avançariam sobre residências. Nesse sentido, é fundamental a manutenção da vegetação.

Na planície fluvio lacustre o papel de filtragem biológica e desintoxicação bioquímica as raízes de muitas plantas, incluindo as halófilas, exercem tal função. São Miguel do Gostoso é um dos municípios potiguares que possuem deficiente sistema de esgotamento sanitário. Nesse sentido, a vegetação arbórea, arbustiva e herbácea presentes, sobretudo na planície costeira, contribui na manutenção da qualidade da água subterrânea e superficial.

O transporte de sedimentos pelos rios é realizado pelos canais que exercem um papel de suprimento de sedimentos para as praias. Por arraste, saltação e suspensão, argilas e areias são deslocadas em direção à jusante dos riachos. Sem essa função dos fluxos de convergência a conexão entre as unidades geoambientais seria minimizada. É sabido que em anos mais chuvosos os cursos fluviais expandem suas planícies de inundação. Assim, algumas comunidades podem estar susceptíveis a enchentes necessitando-se a observação de suas características locacionais.

A proteção contra enchentes é desempenhada pelas áreas de baixio. A função geomorfológica das planícies fluvio lacustres é conter o excedente de águas superficiais verificadas, sobretudo, durante os meses de maior precipitação pluvial. Nos últimos 05 anos as precipitações ficaram bem abaixo da média e os corpos hídricos superficiais praticamente secaram. 
Nos baixos platôs e tabuleiros costeiros, são encontrados principalmente os serviços de polinização que são possibilitados pela vegetação ao recobrir tais compartimentos. Embora em muitos locais a vegetação esteja bastante antropizada, muitos trechos dos tabuleiros e baixos platôs são recobertos por vegetação predominantemente arbórea e arbustiva.

Nos tabuleiros e baixos platôs, o relevo não apresenta mudanças bruscas de cotas altimétricas não oferecendo dificuldades para a construção de moradias. Quando se trata da fauna, a cobertura vegetal funciona como abrigo para determinadas espécies animais, garantindo a manutenção do ecossistema. O controle de pragas e doenças é um dos serviços ligados ao uso da vegetação de acordo com os saberes tradicionais. Realizar a queima de algumas espécies vegetais e criação de animais como galinhas controlam a população de baratas, barbeiros (muitas casas são de taipa) e escorpiões.

Os serviços de manutenção dos fluxos de abastecimentos de água são desempenhados pelas condições climáticas, mas, sobretudo geológicas. A estrutura geológica de São Miguel do Gostoso é sedimentar. Nos baixos platôs Formação Barreiras e sedimentos areno argilosos integram os terrenos que os ecossistemas cultivados e naturais são possibilitados pela existência de solos e condições hídricas.

A configuração geológica de São Miguel do Gostoso, com sua expressão territorial totalmente inserida na bacia potiguar agrega rochas calcárias de idade cretácea fraturadas permitindo a prospecção de águas subterrâneas. Nos tabuleiros costeiros, a utilização de poços permite a irrigação de cultivos e dessedentação dos animais. A Formação Barreiras também apresenta excelentes condições de armazenamento e manutenção da composição química da água doce.

\subsection{Serviços culturais}

De acordo com a MEA (2005), entende-se que serviços ecossistêmicos culturais são, normalmente, definidos como os benefícios não materiais que as pessoas obtêm dos ecossistemas através do desenvolvimento cognitivo, reflexão, recreação, experiências estéticas e religiosas assim criam-se laços entre os seres humanos e seus ambientes naturais 
desenhando assim uma situação de pertencimento íntimo do humano com suas paisagens (Maes Et Al., 2013; Schaich; Bieling; Plieninger, 2010).

Dessa forma, incorporar os serviços culturais na avaliação de serviços ecossistêmicos faz-se necessário devido a crescente contribuição e percepção dos ecossistemas como meio para o bem-estar humano, assim, evitando uma tendência de isolá-los em razão de outros serviços ecossistêmicos (Schaich; Bieling; Plieninger, 2010).

No município de São Miguel do Gostoso os serviços culturais foram identificados e classificados seguindo a metodologia CICES. Percebe-se que estes se distribuem de forma concentrada na unidade geoambiental da Planície Costeira, estando presente também, mas em menor quantidade, no Baixo Platô Interiorano, Tabuleiro Costeiro e na Planície FluvioLacustre/Lagunar.

Conforme padronização estabelecida pela CICES, as divisões de interações espirituais e simbólicas com o ecossistema e de interações físicas e intelectuais com o ecossistema estão subdivididas em grupos mais específicos. A primeira destas é agrupada em espiritual ou emblemática e outros. Já a segunda divisão é agrupada em interações físicas e vivenciais e interações intelectuais e representativas. Os grupos destas divisões dividem-se ainda em classes, de acordo com seus tipos e/ou usos. Sendo assim, a divisão referente às interações espirituais e simbólicas traz 04 classes, sendo elas o simbólico, sagrado ou religioso, existência e legado. Já a divisão em interações físicas e intelectuais divide-se entre as classes de uso de plantas, animais e paisagens, científica, educacional, de herança cultural, de entretenimento e estético. A partir da aplicação da metodologia proposta, deu-se como resultado, o quadro 05.

Para uma melhor visualização dos SE Culturais identificados no município de São Miguel do Gostoso, optou-se por espacializá-los e assim observar a distribuição dos mesmos na malha municipal. O mapa da figura 04 apresenta o resultado desta espacialização. 


\begin{tabular}{|c|c|c|c|c|c|c|c|c|}
\hline \multirow{2}{*}{ DIVISÃO } & \multirow{2}{*}{ GRUPO } & \multirow{2}{*}{ CLASSE } & \multirow{2}{*}{ TIPO DA CLASSE } & \multirow{2}{*}{ EXEMPLOS } & \multicolumn{4}{|c|}{ UNIDADE GEOAMBIENTAL } \\
\hline & & & & & PC & PFL & TC & BPI \\
\hline \multirow{4}{*}{$\begin{array}{l}\text { INTERAÇÕES } \\
\text { ESPIRITUAIS E } \\
\text { SIMBÓLICAS } \\
\text { COM O } \\
\text { ECOSSISTEMA }\end{array}$} & \multirow{2}{*}{$\begin{array}{l}\text { Espiritual ou } \\
\text { emblemática }\end{array}$} & Simbólico & \multirow{2}{*}{$\begin{array}{c}\text { Pelo uso, } \\
\text { plantas, } \\
\text { animais, tipo de } \\
\text { ecossistema }\end{array}$} & $\begin{array}{c}\text { Festa do } \\
\text { Padroeiro dos } \\
\text { Pescadores }\end{array}$ & $\mathrm{x}$ & & & \\
\hline & & $\begin{array}{l}\text { Sagrado ou } \\
\text { religioso }\end{array}$ & & $\begin{array}{l}\text { Rezadeiras e } \\
\text { Raizeiros; } \\
\text { Marco do } \\
\text { Cruzeiro }\end{array}$ & $x$ & & & \\
\hline & \multirow{2}{*}{ Outros } & Existência & \multirow{2}{*}{$\begin{array}{l}\text { Por plantas, } \\
\text { animais, } \\
\text { característica } \\
\text { ou tipo de } \\
\text { ecossistema }\end{array}$} & $\begin{array}{l}\text { Soltura de } \\
\text { filhotes de } \\
\text { tartarugas }\end{array}$ & $x$ & & & \\
\hline & & Legado & & $\begin{array}{c}\text { Praia do Marco } \\
\text { de Touros }\end{array}$ & $\mathrm{x}$ & & & \\
\hline \multirow{6}{*}{$\begin{array}{l}\text { INTERAÇÕES } \\
\text { FÍSICAS E } \\
\text { INTELECTUAIS } \\
\text { COM O } \\
\text { ECOSSISTEMA }\end{array}$} & $\begin{array}{l}\text { Interações } \\
\text { físicas e } \\
\text { vivenciais }\end{array}$ & $\begin{array}{l}\text { Uso de plantas, } \\
\text { animais e } \\
\text { paisagens }\end{array}$ & $\begin{array}{l}\text { Visitas, dados } \\
\text { de uso, plantas, } \\
\text { animais e tipo } \\
\text { de ecossistema }\end{array}$ & $\begin{array}{c}\text { Pesca Artesanal } \\
\text { Familiar; Feiras } \\
\text { livres; } \\
\text { Caminhadas; } \\
\text { Corridas; } \\
\text { Esportes. } \\
\end{array}$ & $\mathrm{x}$ & & & \\
\hline & \multirow{5}{*}{$\begin{array}{l}\text { Interações } \\
\text { intelectuais e } \\
\text { representativ } \\
\text { as }\end{array}$} & Científica & \multirow{5}{*}{$\begin{array}{c}\text { Por uso, } \\
\text { citação, plantas, } \\
\text { animais e tipo } \\
\text { de ecossistema }\end{array}$} & Raizeiros; & $x$ & & & $x$ \\
\hline & & Educacional & & $\begin{array}{l}\text { História do } \\
\text { Marco de } \\
\text { Touros e } \\
\text { especulações } \\
\text { sobre o } \\
\text { descobrimento } \\
\text { do Brasil; } \\
\text { artigos } \\
\text { científicos. }\end{array}$ & $x$ & $x$ & $x$ & $x$ \\
\hline & & Herança cultural & & $\begin{array}{c}\text { Uso da } \\
\text { fitoterapia } \\
\text { Nome do } \\
\text { município }\end{array}$ & $\mathrm{x}$ & $x$ & $x$ & $x$ \\
\hline & & Entreteni-mento & & $\begin{array}{c}\text { Falésias } \\
\text { Praias } \\
\text { Ecoturismo } \\
\text { Festas } \\
\text { (Réveillon) } \\
\end{array}$ & $x$ & & & \\
\hline & & Estético & & $\begin{array}{c}\text { Grande } \\
\text { Tamarineira do } \\
\text { Centro da } \\
\text { Cidade } \\
\text { Pórtico da } \\
\text { entrada } \\
\text { (Retrata velas } \\
\text { das jangadas) }\end{array}$ & $x$ & & & \\
\hline
\end{tabular}

Quadro 05 - Serviços culturais no município de São Miguel do Gostoso por unidade geoambiental. Fonte: Os autores, 2017. 


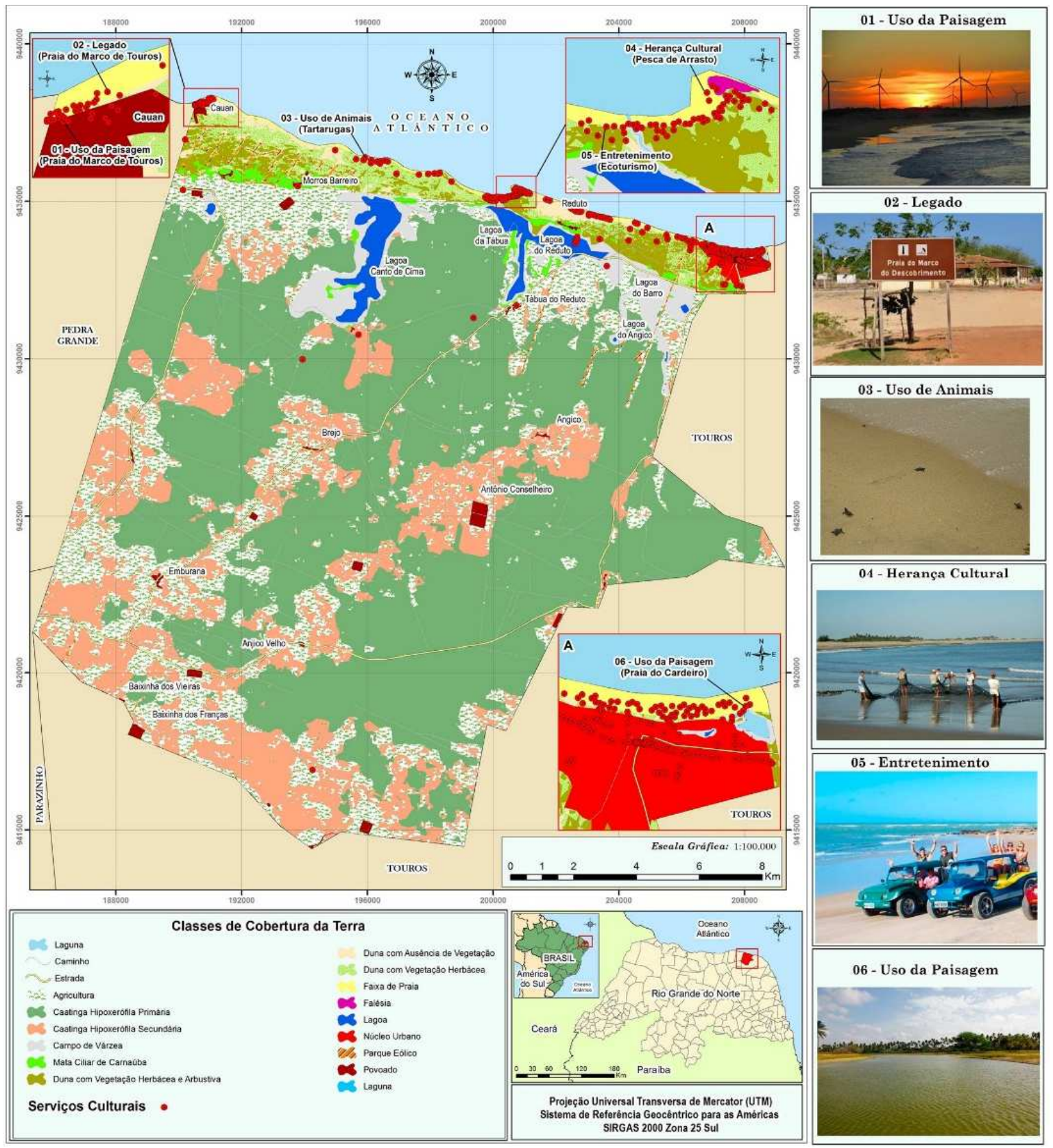

Figura 04 - Mapa de serviços culturais do município de São Miguel do Gostoso-RN Fonte: Os autores, 2017.

\subsection{Interações físicas e intelectuais com o ecossistema}

Os serviços ecossistêmicos culturais, elencados no grupo "espirituais e emblemáticos" são provavelmente os mais difíceis de serem mapeados. Eles exigem conhecimento local ou mapeamento detalhado de recursos paisagísticos (MAES et al., 2013). De toda forma e com 
base nas revisões realizadas e visita ao local observa-se que existe certo simbolismo e ligação da população de São Miguel do Gostoso com o mar, inserindo assim a Festa do Padroeiro nesta lista.

Ainda nas discussões da temática religiosa, observou-se que o município tem forte interação com o Marco de Cruzeiro (lugar de romarias e missas) como também com o ofício das Rezadeiras e Raizeiros que se utilizam do ecossistema local para o desenvolvimento do seu trabalho. Não foi possível, neste trabalho, realizar o georreferenciamento individual destes ofícios.

Ainda na discussão do simbolismo local, a Planície Costeira de São Miguel do Gostoso é área de desova de tartarugas marinhas e a existência de Associações locais como a Associação do Meio Ambiente, Cultura e Justiça Social (AMJUS) no desenvolvimento do trabalho de proteção de ninhos e soltura de filhotes de tartarugas, utilizando-se assim da paisagem como meio de valorização da atividade e dos animais que lá vivem, fazem desta atividade um item importante neste sentido. Conforme visualizado na figura 05.

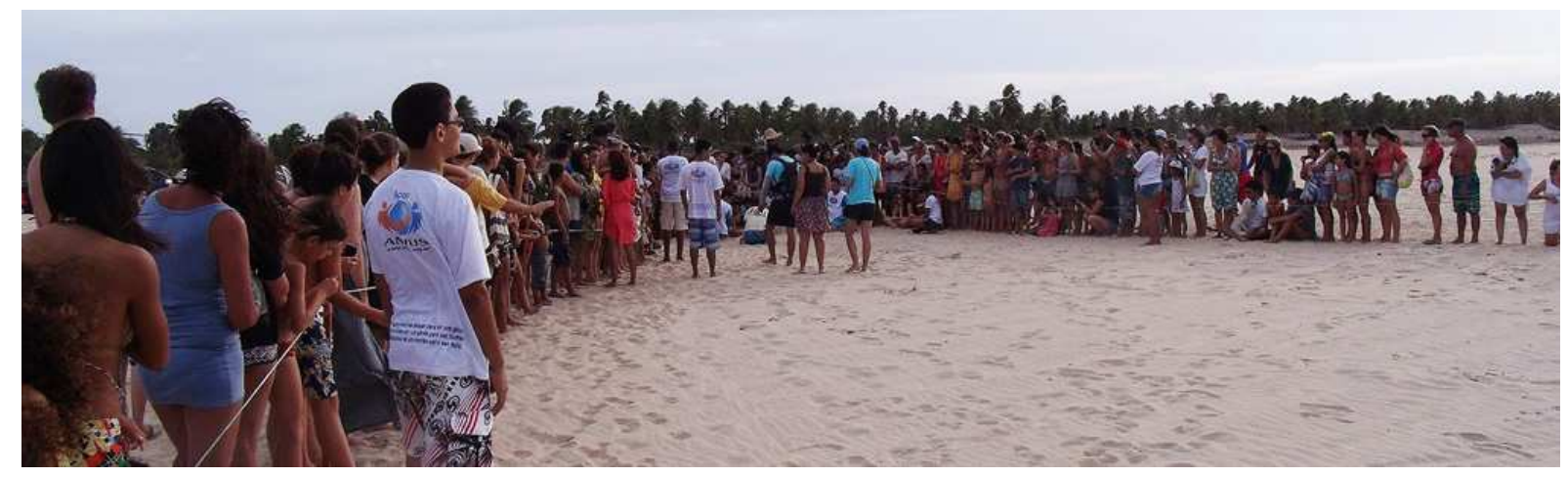

Figura 05: Reunião de moradores de São Miguel do Gostoso. Fonte: Google, 2017.

O Marco de Touros localizado no município, considerando um dos primeiros monumentos da América do Sul, está sempre na discussão sobre a chegada dos portugueses ao Brasil (Teixeira, 2013). O local hoje conta com uma réplica do Marco original, que atualmente encontra-se na Fortaleza dos Reis Magos na capital potiguar. O local onde o mesmo foi fincado recebe até hoje pessoas para realização de missas e orações na capelinha que o rodeia. 


\section{Conclusões}

A elaboração deste artigo nos trouxe a oportunidade de aplicar metodologias pertinentes à identificação e mapeamento de serviços ecossistêmicos, como forma de complementar a análise ambiental do município de São Miguel do Gostoso, de maneira mais integrada. Dessa forma, incorporar a avaliação e mapeamento de serviços ecossistêmicos faz-se necessário devido a crescente contribuição e percepção dos ecossistemas como influência para o bem-estar humano.

Sobre a divisão do município a partir de unidades geoambientais, esta tarefa foi de extrema importância para o resultado final de identificação e mapeamento dos serviços, tendo em vista que as categorias estabelecidas pela CICES puderam ser aplicadas de forma individual, de acordo com as características de cada unidade, trazendo resultados mais coerentes. Os serviços ambientais, de maneira geral, têm seu valor e desempenham um papel importante na motivação do apoio público à proteção dos ecossistemas. Com base no escopo e nos métodos de avaliação aplicados, diferenciamos áreas, saberes, usos e histórias, que podem não apresentar a totalidade do município, mas certamente favorecem o registro inicial dos $\mathrm{SE}$, que podem incluir, mas também se estender além das outras classes.

\section{Referências bibliográficas}

ARROW, K. et al. Economic growth, carrying capacity, and the environment 1. Ecological Economics, v. 268, p. 520-521, 1995.

BRONDÍzIO, E. S. et al. Socio-cultural context of ecosystem and biodiversity valuation. The Economics of Ecosystems and Biodiversity: Ecological and Economic Foundations, n. March, p. 3-29, 2010.

BRASIL. Censo agropecuário. Rio de Janeiro: IBGE, 2006.

BRYAN, B. A.; CROSSMAN, N. D. Impact of multiple interacting financial incentives on land use change and the supply of ecosystem services. Ecosystem Services, v. 4, p. 60-72, 2013.

CHAN, K. M. A.; SATTERFIELD, T.; GOLDSTEIN, J. Rethinking ecosystem services to better address and navigate cultural valuesEcological Economics, 1 jan. $2012 . \quad$ Disponível em: <https://open.library.ubc.ca/clRcle/collections/facultyresearchandpublications/52383/items/1.0132715>. Acesso em: 1 jul. 2017

COSTANZA, R. What is ecological economics? Ecological Economics, v. 1, n. 1, p. 1-7, 1989. 
COSTANZA, R. et al. The value of ecosystem services: putting the issues in perspectives. Ecological Economics, v. 25, p. 67-72, 1997a.

COSTANZA, R. et al. The value of ecosystem services: putting the issues in perspectives. Ecological Economics, v. 25, p. $67-72,1997 b$.

COSTANZA, R. et al. Changes in the global value of ecosystem services. Global Environmental Change, v. 26, n. 1, p. 152-158, 2014.

DALY, H.; FARLEY, J. Ecological economics: principles and applicationsEcological Economics, 2010. Disponível em: <http://indomarine.webs.com/documents/Ecological_Economics_Principles_And_Applications.pdf>. Acesso em: 1 jul. 2017

DANIEL, T. C. et al. Contributions of cultural services to the ecosystem services agenda. Proceedings of the National Academy of Sciences, v. 109, n. 23, p. 8812-8819, 5 jun. 2012.

DE GROOT, R. S.; WILSON, M. A.; BOUMANS, R. M. J. A typology for the classification, description and valuation of ecosystem functions, goods and services. Ecological Economics, v. 41, n. 3, p. 393-408, 2002.

HAINES-YOUNG, Roy; POTSCHIN, Marion. Common International Classification of Ecosystem Services (CICES): Consultation on Version 4, August-December. EEA - Framework Contract, n. EEA/IEA/09/003. Nottingham: University of Nottingham/Centre for Environmental Management, 2013.

INSTITUTO DE DESENVOLVIMENTO SUSTENTÁVEL E MEIO AMBIENTE DO RIO GRANDE DO NORTE. No Title. Disponível em: <http://adcon.rn.gov.br/ACERVO/idema/DOC/DOC000000000013844.PDF>. Acesso em: 3 jul. 2017.

MAES, J. et al. Mapping ecosystem services for policy support and decision making in the European Union. Ecosystem Services, v. 1, n. 1, p. 31-39, 2012.

MAES, J.; CROSSMAN, N. D.; BURKHARD, B. 15 . MAPPING ECOSYSTEM SERVICES The cascade model as a framework for mapping ecosystem services. v. 1, p. 188-204, 2016.

MILLENNIUM ECOSYSTEM ASSESTMENT. Ecosystems and human well-being. [s.I: s.n.]. v. 5

PLIENINGER, T. et al. Assessing, mapping, and quantifying cultural ecosystem services at community level. Land Use Policy, v. 33, p. 118-129, 2013.

RIO GRANDE DO NORTE. Perfil do seu município: São Miguel do Gostoso. Natal: SEMARH, 2008.

SÃO MIGUEL DO GOSTOSO. Disponível em: <http://natalbrasil.tur.br/polo-costa-das-dunas/sao-miguel-dogostoso/> Acesso em: 12 de julho de 2017.

SCHAICH, H.; BIELING, C.; PLIENINGER, T. The Cultural Landscape Paradigm Linking Ecosystem Services with Cultural Landscape Research. n. 4, p. 269-277, 2010.

SHERROUSE, B. C.; CLEMENT, J. M.; SEMMENS, D. J. A GIS application for assessing, mapping, and quantifying the social values of ecosystem services. Applied Geography, v. 31, n. 2, p. 748-760, 2011.

TEIXEIRA, T. M. Da F. Arraial do Marco: nosso porto seguro. 1. ed. Natal/RN: Martins Fontes, 2013. 